\title{
STIFFNESS CHANGES DUE TO STATIC LOADING OF A BRICK ARCH
}

\author{
JAN BAYER ${ }^{1}$, SHOTA URUSHADZE ${ }^{1 *}$ AND JIŘÍ WITZANY ${ }^{2}$ \\ ${ }^{1}$ Institute of Theoretical and Applied Mechanics of the Czech Academy of Sciences \\ Prosecká 809/76, 19000 Praha 9, Czech Republic \\ e-mail: \{bayer@itam.cas.cz, urushadze@itam.cas.cz\},www.itam.cas.cz (*corresponding author) \\ ${ }^{2}$ Czech Technical University Prague, Faculty of Civil Engineering \\ Thakurova 7, 16629 Prague 6 - Dejvice, Czech Republic \\ email: witzany@fsv.cvut.cz,www.fsv.cvut.cz
}

Keywords: Masonry arch, impact testing, static loading, stiffness evaluation, flexibility change

\begin{abstract}
A brick arch was loaded under laboratory conditions in three successive loading steps. No cracks were observed but reduction of natural frequencies and stiffness of the arch was experimentally documented. The stiffness was evaluated in a non-destructive test using an impact hammer and only two accelerometers. The proposed identification technique based on known experimental modal analysis theory is tailored to stiffness evaluation of masonry vaults. The results and the applied method are extensively discussed.
\end{abstract}

\section{INTRODUCTION}

Modal parameters reflect stiffness changes in building structures and are therefore applied in the framework of health monitoring, estimated in order to detect possible damage in structures or just to check the integrity of finite element models $[1,2,3]$.

Application of experimental modal analysis to masonry structures (overview [4]) is less common than to bridges, but there are numerous tests of churches [5,6,7] and publications dedicated to the dynamic behaviour of masonry arches. The presented article follows up on investigations performed in the nighties in England $[8,9,10]$ and applies similar approach as [11]. A good example of laboratory research appeared recently in [12].

Brittle materials that form cracks under static loading are more suitable to vibration based damage detection than steel structures or pre-stressed concrete. On the other hand, they are likely to behave in a non-linear way which makes the application of experimental modal analysis questionable. Experience with similar structures shows that the influence of nonlinear effects (probably mainly due to damping) increases with distance from the excitation (loading) point, and the dynamic response of the structure depends on loading location [13]. 
The proposed experimental procedure therefore only uses measured driving point frequency response functions (FRF) for the evaluation of the condition of the investigated brick arch. It does not extract the modal properties but instead estimates the static flexibility from the FRFs directly. The experimentally obtained flexibility increases with applied static load as the measured response to the hammer impact confirmed.

The proposed method is therefore possibly applicable in the health monitoring of brick vaults as well as in the experimental assessment of the collapse mechanism of masonry arches.

\section{STATIC FLEXIBILITY ESTIMATION}

Flexibility (which is the inverse of stiffness) has been successfully applied for damage detection in the past [14]. The main advantage is that it converges early with the few first modes when derived from measured results.

Static flexibility can be estimated as the frequency response function (receptance) at zero frequency $[8,15]$. The FRF at each driving point can be approximated as the sum of as many single degrees of freedom (SDOF) systems as there are distinct frequency peaks in the particular FRF for each driving point independently.

The FRFs were obtained from hammer impacts, and the driving (hitting) points were selected at regular distances alo to measure the vibratio selected. It was measured only int accelerometers were in

In order to estimate the FRFs at the zero frequency it is necessary to perform a curve fit and

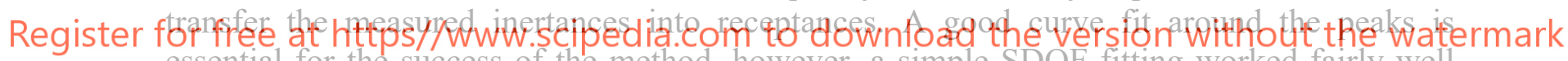
essential for the success of the method, however, a simple SDOF fitting worked fairly well here. The dominant peak frequencies were estimated from the summarized FRF, and then a simple amplitude fitting was performed. Application of more sophisticated fitting methods is planned next.

\section{ANALYSIS}

In order to check the credibility of the experimental results a linear finite element (FE) model was created in ANSYS 17.2 using Solid185 elements. First comparisons of the measured and computed results confirmed that the boundary conditions were close to the clamped state. After adjustment of the elasticity modulus to $3 \mathrm{GPa}$ and the density to $1700 \mathrm{~kg} / \mathrm{m} 3$ the natural frequencies roughly corresponded to the measured ones (see Tab.1). This model was used to compute the static deformations due to unitary static load at measured locations which correspond to the experimentally evaluated flexibilities (see Fig.3). Only the intact condition was simulated. 
Table 1: Comparison of computed and measured natural frequencies for the intact condition

\begin{tabular}{|c|c|c|}
\hline Mode No. & Analytical Frequencies [Hz] & Experimental Frequencies [Hz] \\
\hline 1 & 28,52 & 30,7 \\
\hline 2 & 35,32 & 32,4 \\
\hline 3 & 55,75 & 52,0 \\
\hline
\end{tabular}

\section{EXPERIMENT}

The experimental site is shown in Figure 1. The radius of the arch was $1.625 \mathrm{~m}$, its span was $3 \mathrm{~m}$ and width $0.75 \mathrm{~m}$. Accelerations were measured with the transducers SKF CMSS 793L in two rows of measured points perpendicularly to the surface at equal distances of approximately $255 \mathrm{~mm}$. The 8202 Brüel\&Kjaer impact hammer was used to hit the surface of the arch between the measured points with a peak force of approximately $400 \mathrm{~N}$. The sampling rate of $1 \mathrm{kHz}$ was used and the time for each measurement point took cca $120 \mathrm{~s}$ including five impacts for averaging.

After the dynamic experiments on the intact arch the static force of 24, 36, $48 \mathrm{kN}$ (x2) was applied in three successive steps at the $1 / 3$ points. After each loading step dynamic impact

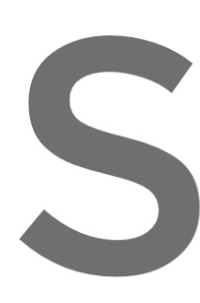
measurements were 2 x129 kN total force
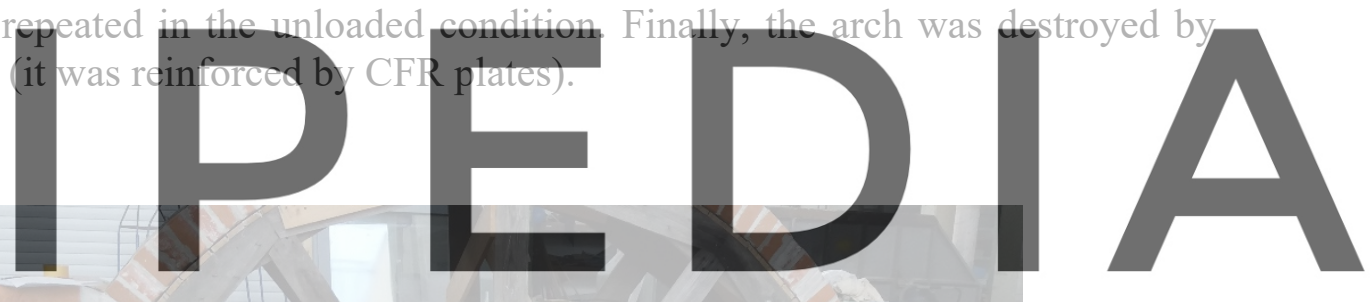

Register for free at https//www.scipedia.com to download the version without the watermark

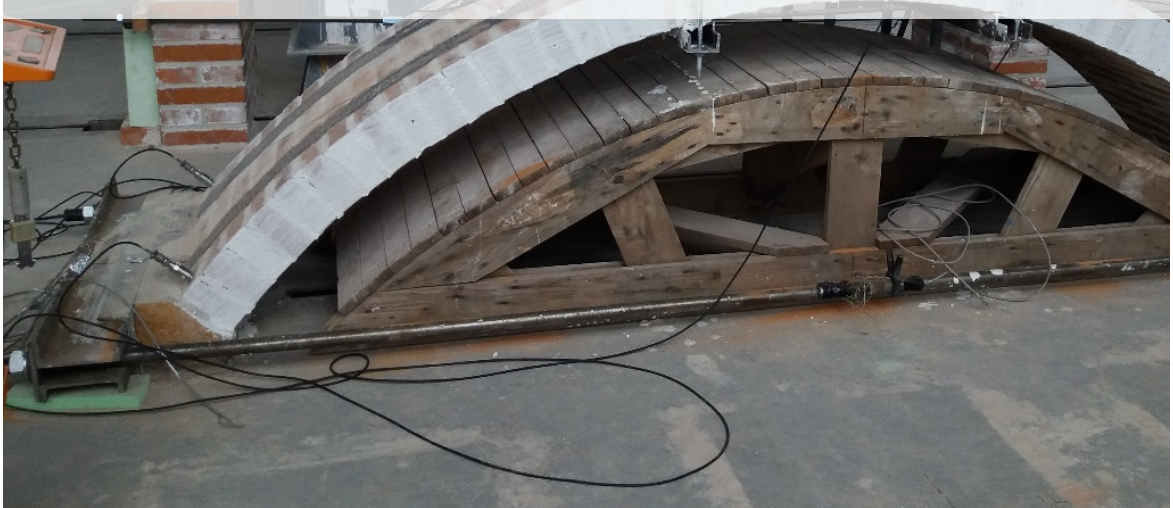

Figure 1: Experimental site (note the two moving accelerometers at the vault's heel) 
In spite of the fact that no cracks could be observed on the arches after the stage where $48 \mathrm{kN}$ was applied, the shifts in frequency spectra (see Fig.2) and the evaluated flexibilities (see Fig.3) revealed a gradual loss of stiffness. This drop in stiffness was not confirmed however by the deformations measured during the static loading. The hypothetical explanation for this phenomenon may be a possible development of micro cracks.

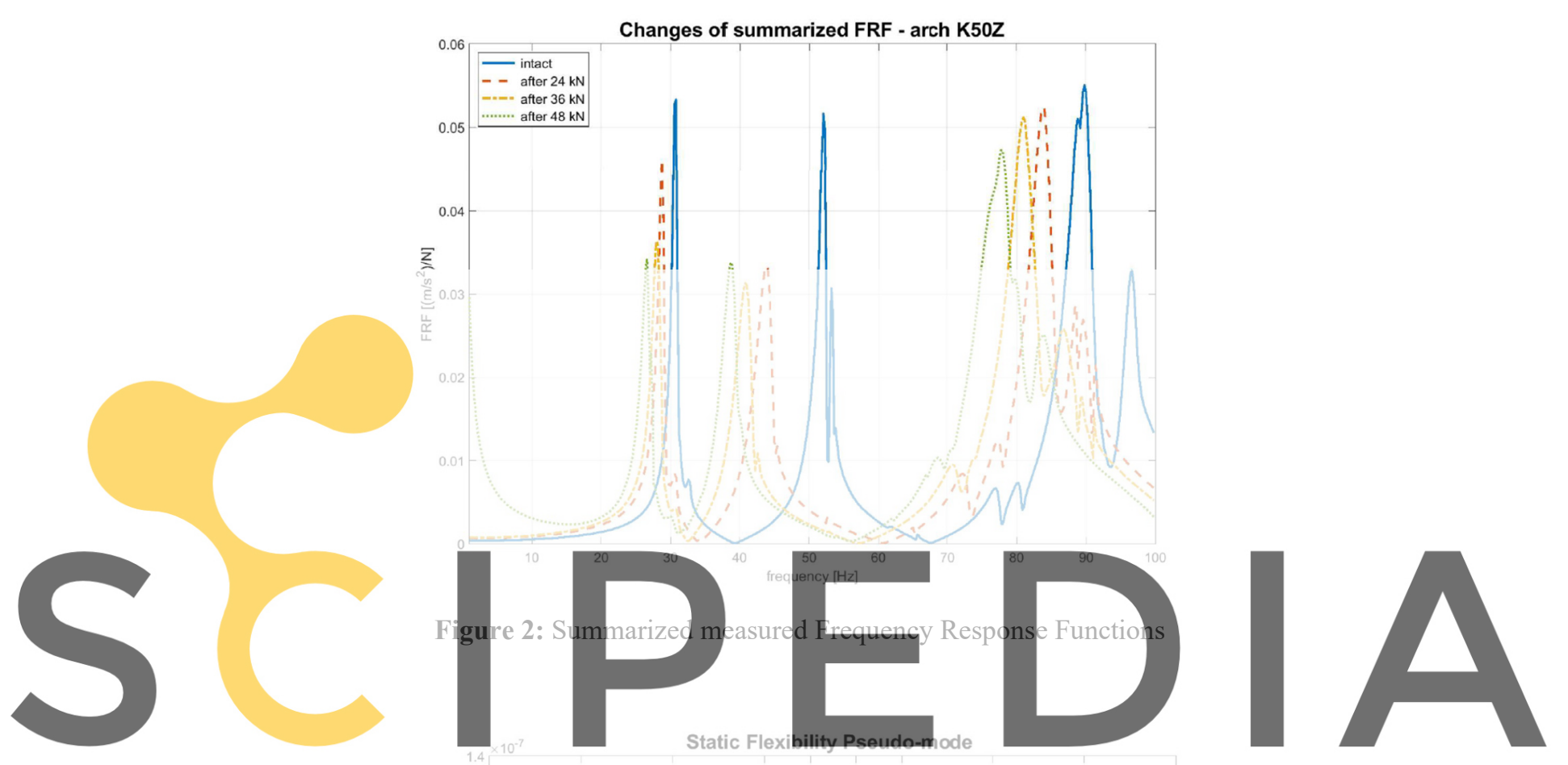

Register for free at https//www.scipedia.com to download the version without the watermark

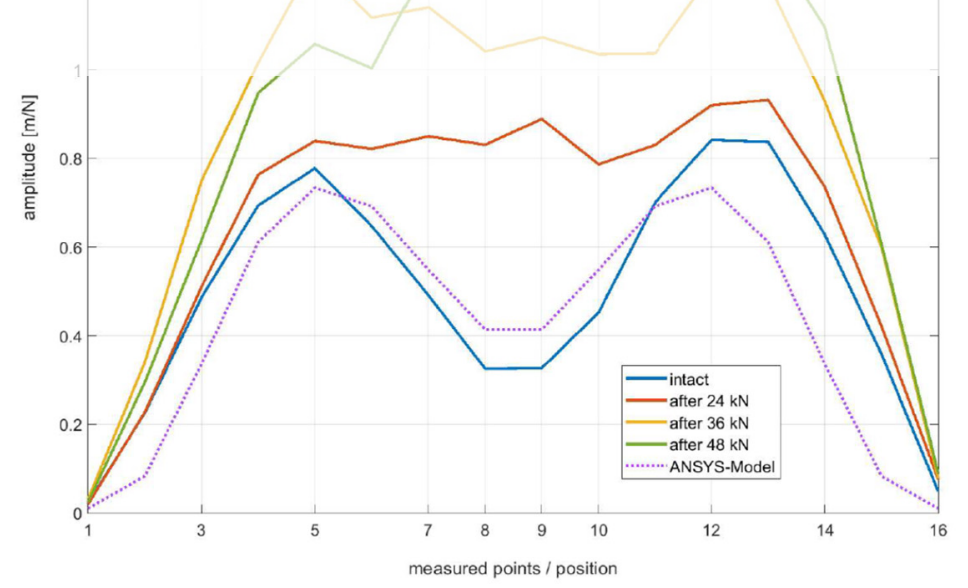

Figure 3: Experimentally estimated calculated flexibility 
The increase in flexibility (or loss of stiffness) can be plotted relatively to the intact condition (see Fig.4) showing that the major damage occurred in the middle of the arch. This indicates that the experimentally estimated flexibilities could potentially be used to predict the failure mode which is sometimes a problem with ageing masonry structures, as mentioned in [10].

\section{CONCLUSIONS AND DISCUSSION}

The completed experiments showed that the dynamic properties of the tested masonry arch were influenced by the applied static load. The estimated flexibilities and the drop in natural frequencies indicate a gradual loss of arch stiffness due to the static loading. However, no significant drop in stiffness was observed during the static loading. A possible explanation may be that the behaviour of the arch at very low vibration levels (induced by the impact hammer) is influenced by micro cracking and is therefore of a different character than static behaviour under substantial static load.

The experimentally estimated flexibilities will therefore not be reliable in predicting static deformations of masonry structures - unlike steel structures [16] - but they could possibly be applied to predict failure modes after further research.

The tested arch was a bare structure without infill or permanent static loads, which made the dynamic testing easier. However, further application of the proposed procedure to test its applicability to the condition assessment of ageing masonry structures seems reasonable.
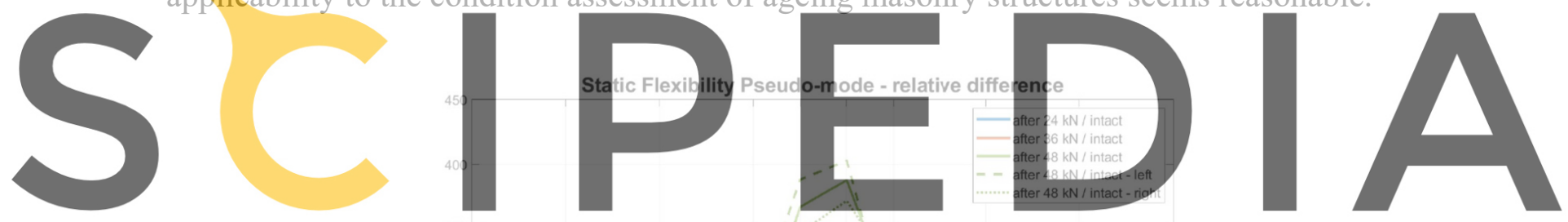

Register for free at https//www.scipedia.com to download the version without the watermark

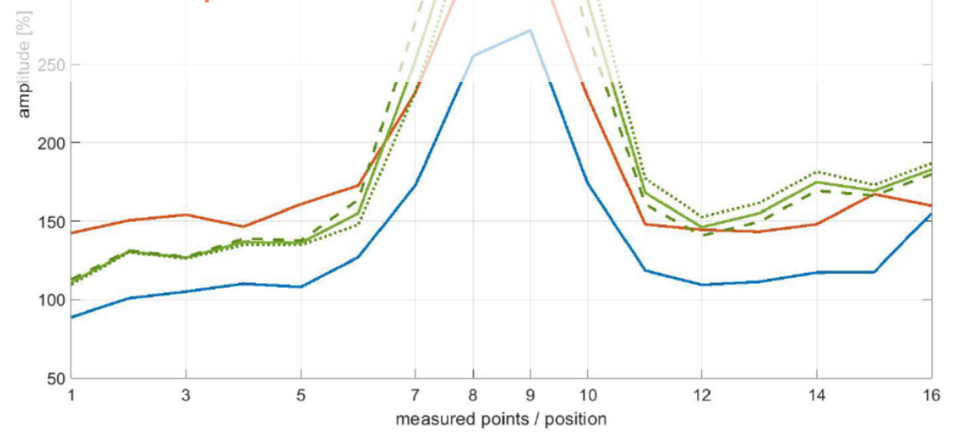

Figure 4: Relative Increase of Flexibility

Acknowledgements. The tested structure and the static part of the tests were completed thanks to the funding provided by NAKI DG16P02M055 "Development and Research of Materials, Methods and Technologies for the Restoration, Preservation and Strengthening of Historic 
Masonry Constructions and Surfaces and Systems of Preventive Conservation of Cultural Heritage Buildings Threatened by Anthropogenic and Natural Hazards" and the dynamic tests and their evaluation was done in the framework of the grant project DG18P02OVV040 "Monuments in motion"; NAKI programs provided by the Ministry of Culture of the Czech Republic.

\section{REFERENCES}

[1] Rücker W., Hille F. Rohrmann R., Guideline for Structural Health Monitoring, BAM, SAMCO, F08a, Berlin 2006

[2] Maeck J., De Roeck G., Dynamic bending and torsion stiffness derivation from modal curvatures and torsion rates, JSV 225(1), 1999, p.153-170 (cracks)

[3] Sinou J-J., A review of damage detection and health monitoring of mechanical systems from changes in the measurement of linear and non-linear vibrations, Robert C. Sapri. Mechanical Vibrations: Measurement, Effects and Control, Nova Science Publishers, Inc., pp.643-702, 2009, 978-1-60692-037-4. <hal-00779322>, https://hal.archivesouvertes.fr/hal-00779322

[4] Cescatti E., Combined experimental and numerical approaches to the assessment of historical masonry structures, Dissertation, PHD, University of Trento, 2016

[5] Ramos L., Marques L., Lourenço P., De Roeck G., Campos-Costa A., Roque J., Monotoring of historical masonry structures with op rational modal anaiysis: two casq studies, July 2010, Mechanical Systems and Signal Proces:
10.1016/j.ymssp. 2010.01.011
Atamturktur S., Hemez F., Unal C., Calibration Under
Models of Masonry Monuments, Los Alamos report. LA Atamturktur S., Famning P., Boothby T. I

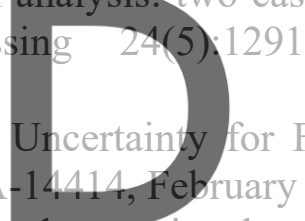
masonry vaults, Engineering and Computational Mechanics 163, September 2010 Issue

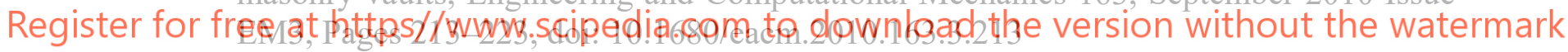

[8] Armstrong D.M., Sibbald A., Forde M.C., Integrity assessment of masonry arch bridges using the dynamic stiffness technique, NDT\&E International, vo1. 28, No.6, pp. 367-375, 1995

[9] Brown G., Pretlove A.J., Ellick J.C.A., Hogg V, Choo B.S., Changes in the dynamic characteristic of a masonry arch bridge subjected to monotonic loading to failure, Proc. of the First International Conference on Arch Bridges held at Bolton, UK on 3-6 September 1995, p.375-383

[10] Hughes T.H., The testing, analysis and assessment of masonry bridges, Structural Analysis of Historical Constructions, P. Roca, J.L. González, A.R. Marí and E. Onate (Eds.) (C) CIMNE, Barcelona 1996

[11] Heiland D., Mistler M., Investigation of dynamic performance of LASER building, report Nr. 40-10252-01-D1 for ELI Beamlines, Prag, 12/2015, Baudynamik Heiland \& Mistler GmbH, Bergstraße 174, 44807 Bochum, internet: www.baudynamik.de

[12] Masciotta M-G. at al., Dynamic characterization of progressively damaged segmental masonry arches with one settled support: experimental and numerical analyses, Frattura ed Integrità Strutturale, 51 (2020) 423-441; DOI: 10.3221/IGF-ESIS.51.31 
[13] Sortis, A. D., Antonacci, E., and Vestroni, F. 2005, "Dynamic Identification of a Masonry Building Using Forced Vibration Tests," Engineering Structures, Vol. 27, pp. $155-165$.

[14] Reynders E., De Roeck G., A local flexibility method for vibration-based damage localization and quantification, Journal of Sound and Vibration 329 (2010) 2367-2383, https://doi.org/10.1016/j.jsv.2009.04.026

[15] Ewins D.J., "Modal Testing, Theory, Practice, and Application" ISBN-10: 0863802184, Mechanical Engineering Research Studies: Engineering Dynamics Series, 1984, 2nd Edition

[16] Pasha H., Allemang R. J., Phillips A. W., Young A., Poland J., Estimation of Bending Compliance (Stiffness) from Free-Free FRF Measurements: eBCF Theory Experimental Techniques, Rotating Machinery, and Acoustics, Volume 8, DOI: 10.1007/978-3-31915236-3_14, January 2015
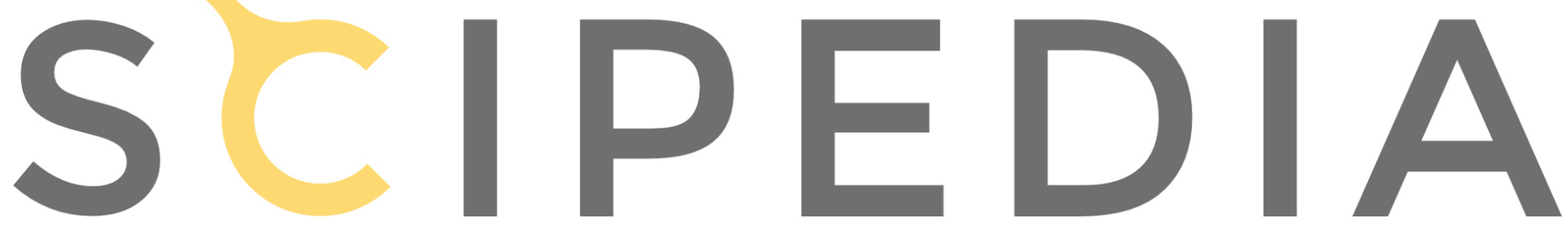

Register for free at https//www.scipedia.com to download the version without the watermark 